Original article

\title{
Monitoring austral and cyclonic swells in the "Iles Eparses" (Mozambique channel) from microseismic noise
}

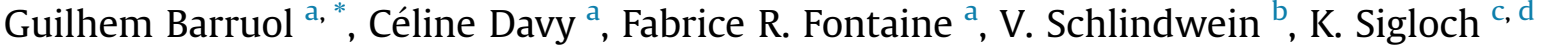 \\ a Laboratoire GéoSciences Réunion, Université de La Réunion, Institut de Physique du Globe de Paris, Sorbonne Paris Cité, UMR CNRS 7154, Université Paris \\ Diderot, 97744, Saint Denis, France \\ ${ }^{\mathrm{b}}$ Alfred-Wegener-Institut, Helmholtz-Zentrum für Polar- und Meeresforschung, Bremerhaven, Germany \\ ${ }^{c}$ University of Oxford, Earth Sciences Department, South Parks Road, Oxford, OX1 3AN, UK \\ d Department of Earth and Environmental Sciences, Ludwig-Maximilians-Universität München, Munich, Germany
}

\section{A R T I C L E I N F O}

\section{Article history:}

Received 6 October 2015

Received in revised form

27 October 2015

Accepted 27 October 2015

Available online 11 November 2015

\section{Keywords:}

Microseismic noise

Swell

Tropical storm

Cyclone

Iles eparses

Mozambique channel

\begin{abstract}
A B S T R A C T
We deployed five broadband three-components seismic stations in the Iles Eparses in the south-west Indian Ocean and on Mayotte Island, between April 2011 and January 2014. These small and remote oceanic islands suffer the effects of strong ocean swells that affect their coastal environments but most islands are not instrumented by wave gauges to characterize the swells. However, wave action on the coast causes high levels of ground vibrations in the solid earth, so-called microseismic noise. We use this link between the solid earth and ocean wave activity to quantify the swells locally. Spectral analyses of the continuous seismic data show clear peaks in the $0.05-0.10 \mathrm{~Hz}$ frequency band (periods between 10 and $20 \mathrm{~s}$ ), corresponding to the ocean wave periods of the local swells. We analyze an example of austral swell occurring in August 2013 and a cyclonic event (Felleng) that developed in January 2013, and quantify the ground motion at each station induced by these events. In both cases, we find a linear polarization in the horizontal plane with microseismic amplitude directly correlated to the swell height (as predicted by the global swell model WaveWatchIII), and a direction of polarization close to the predicted swell propagation direction. Although this analysis has not been performed in real time, it demonstrates that terrestrial seismic stations can be efficiently used as wave gauges, and are particularly well suited for quantifying extreme swell events. This approach may therefore provide useful and cheaper alternatives to wave buoys for monitoring swells and the related environmental processes such as beach erosion or coral reef damages.
\end{abstract}

() 2015 Elsevier Masson SAS. All rights reserved.

\section{Introduction}

The Iles Eparses in the western Indian Ocean consist of the islands of Europa, Juan de Nova and Glorieuses in the Mozambique Channel and by Tromelin Island located ca $400 \mathrm{~km}$ east of Madagascar. Their fragile environments may suffer from anthropogenic activity but have also to face the environmental impact of combined ocean and atmosphere activity. In particular, oceanic swell events generated by local or distant storms may hit these islands hard, strongly affecting their reef barriers and their shorelines, and resulting in coral destruction and beach erosion by sediment transport. Climate change could possibly worsen this

\footnotetext{
* Corresponding author. Laboratoire GéoSciences Réunion, Université de La Réunion, 15 avenue René Cassin, CS 92003, 97744, Saint Denis cedex 9, France.

E-mail address: guilhem.barruol@univ-reunion.fr (G. Barruol).
}

impact. Hence, more and longer-term observations are highly desirable, even if they are proxy observations of swell activity rather than actual wave-gauge data.

Here, a temporary network of five three-component broadband seismic stations (Fig. 1), which was deployed in the Iles Eparses and on Mayotte Island primarily for the study of deep earth structure (Barruol and Sigloch, 2013), is re-purposed to quantify local swell activity in terms of amplitude (swell parameter $H s$ ), period (swell parameter $T p$ ), and direction of propagation (swell parameter $D p$ ). With the exception of Mayotte, these islands are only a few kilometres in diameter, located in harsh and remote environments, and all but Mayotte have been declared terrestrial and marine protected areas to preserve the natural environment and local biodiversity.

Quantifying local swells on remote islands requires direct or indirect observations to determine wave heights, periods and directions of propagation. Numerical models such as the NOAA 


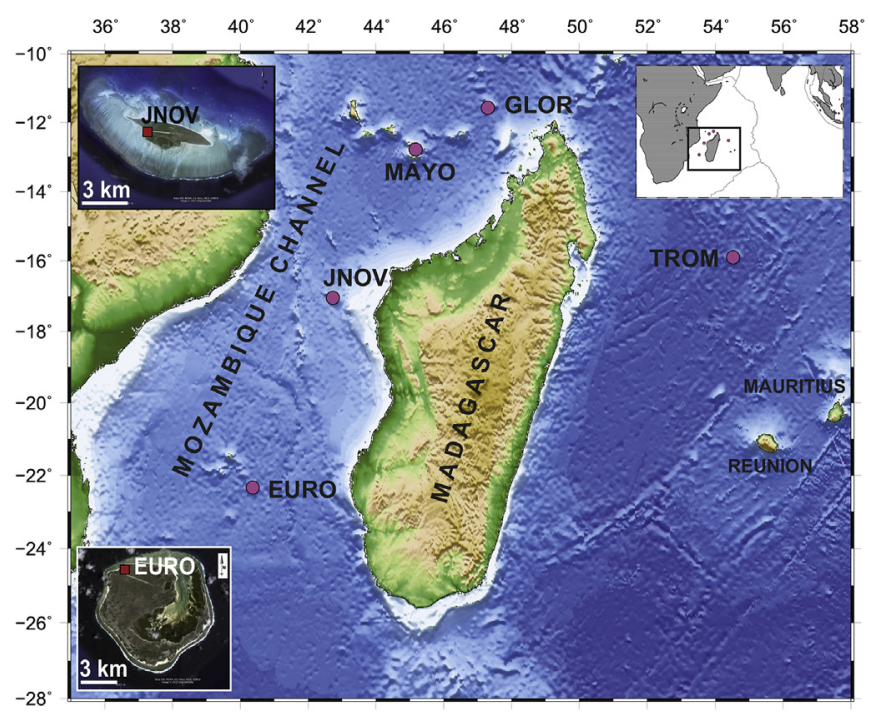

Fig. 1. Location of the seismic stations deployed in the Iles Eparses around Madagascar. Inserts show satellite images of Europa and Juan de Nova Islands, and the locations of the seismic stations.

WaveWatchIII model (hereafter called WWIII) (Tolman and Chalikov, 1996) are available at global scale, but their spatial resolution is rather poor $\left(0.5^{\circ}\right)$ and does not take into account the local interaction of swell with small islands such as those present in the Mozambique Channel. Direct and local swell observations are very scarce in the Indian Ocean and absent in the Mozambique Channel, motivating our approach to characterize swells from indirect seismological observations. These novel seismological proxies for oceanic activity may be relatively easy to acquire and can be efficiently used to evaluate the local impact of waves on the coastal environment of the islands.

After discussing the origins of various oceanic sources of microseismic noise in Section 2, we present the seismic network, the data, and our analyses, performed mostly on so-called "primary" microseisms (Section 3). We compare in some detail swell characteristics recorded during an austral swell event in the Mozambique Channel in August 2013 (Section 4) and during the passage of cyclone Felleng over Tromelin Island in January 2013 (Section 5). By "austral swell", we mean ocean waves arriving from the southern part of the Indian Ocean, generated by powerful storms and over long fetch distances, and that propagate northward over long distances with little attenuation and as coherent wave packages. "Cyclonic swell" has the same mechanism of excitation and propagation, except that the generating storms are tropical storms, called "cyclones" in the Indian Ocean, which may develop much closer to the (tropical) Iles Eparses. Section 6 analyzes seismic signals at the Iles Eparses over longer periods of several months and demonstrates that the main swell events can be well retrieved and quantified from seismic data.

\section{Origins of microseismic noise}

The present work is based on the analysis of the seismic "noise" generated by ocean swell and transmitted to the solid earth as seismic waves that may be recorded by terrestrial seismological instruments (e.g., Friedrich et al., 1998). This noise is called "microseismic" because it consists of continuous ground displacement of a few micrometers, as opposed to sudden, strong earthquake arrivals. It is well visible on individual seismic energy spectra that represent the distribution of noise energy as function of frequency for a given time period. Fig. 2a shows the noise power spectral density of the three seismometer components of station EURO and for two different time periods: during a quiet period before an austral swell event, on Aug. 18, 2013 and during this swell event two days later, on Aug. 20, 2013. The spectra of Fig. 2a show two clear peaks in separate frequency bands that characterize the two kinds of seismic noise, classically split into primary and secondary microseisms (hereafter named PM and SM, respectively). They represent different physical processes involving local or distant sources of ocean wave activity, briefly described below.

Primary microseisms (PM in Fig. 2a), on which we focus the present paper, are generally visible at coastal and island stations and accepted to be generated through direct interaction of swellinduced pressure variation on the sloping seafloor close to the shore (Hasselmann, 1963; Cessaro, 1994; Barruol et al., 2006). Such primary microseismic noise sources have the same periods as the ocean swell (between 8 and $20 \mathrm{~s}$ ) and are accepted to be generated by the local interaction of swell with the sea floor in coastal areas, where water depths becomes shallower than about half the swell wavelength (Darbyshire and Okeke, 1969). Analyzing microseismic noise in this PM frequency band is therefore a way to characterize the local impact of swell on the shore. Comparing noise spectra in Fig. 2a before and after the arrival of a strong swell event, evidences a strong increase of the noise peak in the PM frequency band (at periods close to $20 \mathrm{~s}$ ) on all three components of station EURO. The seismic spectra obtained during a quiet period two days before the swell arrival (light colours in Fig. 2a) have much lower amplitudes in both the SM and PM bands. The spectrogram covering this time period (Fig. 2b) clearly shows the development of the PM associated with this swell arrival. It also shows the swell dispersion effect, with long period swell travelling faster across the oceans than short period swell, explaining the slope observed in the arrival of the PM energy over time.

Secondary microseisms (SM in Fig. 2a) dominate seismic noise worldwide at both continental and oceanic stations. This noise exhibits a large peak at half the period of ocean waves (typically between 3 and $10 \mathrm{~s}$ ) and is widely accepted to be excited by a depth-independent, second-order pressure fluctuation generated by interference of swells (water waves) of similar periods travelling in opposite directions (Longuet-Higgins, 1950). This nonlinear process generates stationary ocean waves whose pressure fluctuations on the seafloor excite seismic surface waves, specifically Rayleigh waves. These are polarized in the vertical plane with an elliptical retrograde particle motion and can propagate over large distances in the solid earth, with little attenuation. Secondary microseisms can be generated in the deep oceans and at large distances from coastal areas (e.g., Essen et al., 2003; Ardhuin et al., 2011; Obrebski et al., 2012; Davy et al., 2014). For the Indian Ocean, the dominant sources have been located in the southernmost part of the basin, associated with large atmospheric lowpressure systems moving around Antarctica (Reading et al., 2014; Davy et al., 2015) but they can also be generated by major tropical storms (Davy et al., 2014).

Although secondary microseisms may provide information concerning distant storms, stationary ocean waves and SM can also be generated by coastal reflection of waves (e.g., Bromirski and Duennebier, 2002; Beucler et al., 2014). If incident and reflected waves propagate in opposite directions, the incoming swell may interfere with its reflected swell, resulting in the generation of standing waves in coastal areas, oscillating at twice the frequency of the propagating wave (Bromirski et al., 2005). Some observations suggest that local and distant sources of noise in the SM frequency peak may coexist (e.g., Chevrot et al., 2007; Koper and Buriaciu, 2015). In the present study, it may be the case for station EURO 

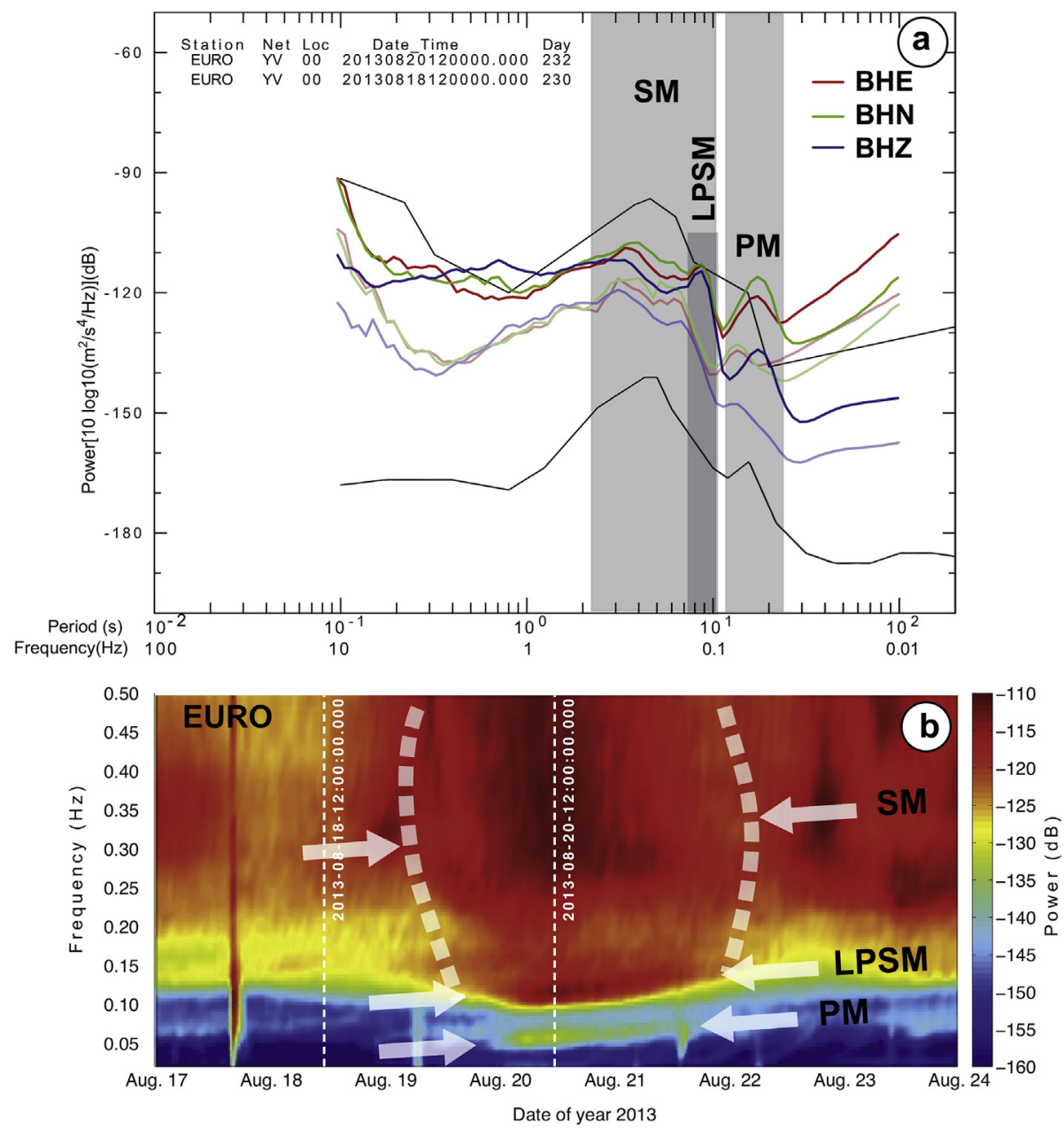

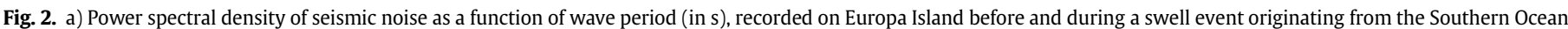

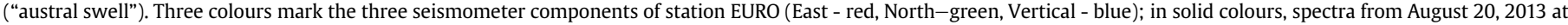

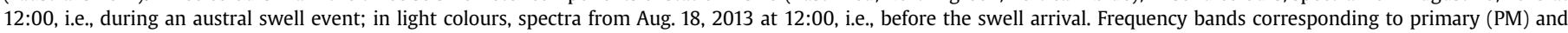

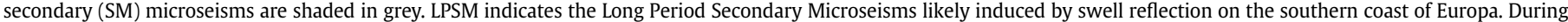

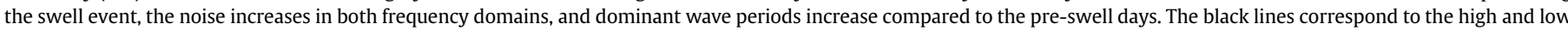

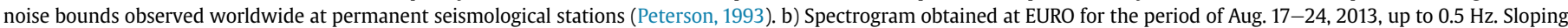

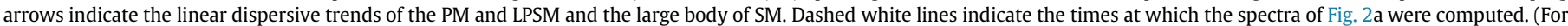
interpretation of the references to colour in this figure legend, the reader is referred to the web version of this article.)

(on Europa Island), which displays a small energetic peak in the long period part of the SM (Fig. 2a). This peak is referred to as LPDF in the literature (Long Period Double Frequency) (Bromirski et al., 2005; Koper and Buriaciu, 2015) and LPSM in the present paper. The spectrogram exhibits a clear peak in the SM band around $8 \mathrm{~s}$, i.e., at twice the PM frequency, with the same slope than the PM energy, suggesting the presence of a SM source close to the island (likely on its southern side). This feature corresponds to the LPSM peak observed on the spectra Fig. 2a and is likely the signature of an interaction between the incoming austral swell and the ocean waves reflected off the southern shore of Europa, providing evidence for local SM sources close to the island and induced by swell coastal reflection.

\section{Data and methods}

\subsection{Seismological network}

A seismic network of five broadband stations (Fig. 1) was deployed during the April 2011 cruise of the French vessel "Marion
Dufresne" in the frame of the "Iles Eparses" research program. Station locations and recording periods are presented in Table 1. These stations were deployed in these remote islands to extend toward the west the RHUM-RUM seismic network (Réunion Hotspot and Upper Mantle - Réunions Unterer Mantel) centred on La Réunion Island in order to investigate the mantle structure beneath the active hotspot (Barruol and Sigloch, 2013).

Each of the five broadband seismic stations was equipped with a Guralp sensor CMG-3ESPC that continuously measured a signal

Table 1

Location and recording periods (year-day) of the broadband seismic stations. Due to technical failures, recording capacities, and logistical difficulties in reaching the islands, there were recording gaps at some stations.

\begin{tabular}{lllll}
\hline Station & Lat. $\left({ }^{\circ} \mathrm{N}\right)$ & Long $\left({ }^{\circ} \mathrm{E}\right)$ & Start recording & End recording \\
\hline EURO & -22.34399 & 40.34006 & $2011-096$ & $2013-343$ \\
JNOV & -17.05428 & 42.71255 & $2011-101$ & $2013-341$ \\
MAYO & -12.84558 & 45.18681 & $2011-105$ & $2014-014$ \\
GLOR & -11.58242 & 47.28952 & $2011-108$ & $2013-345$ \\
TROM & -15.88852 & 54.52177 & $2011-113$ & $2013-350$ \\
\hline
\end{tabular}


proportional to ground velocity along three components (one vertical and two horizontal, aligned along the NS and EW directions), at frequencies between $120 \mathrm{~s}$ and $50 \mathrm{~Hz}$. The data were digitized at 40 samples/s by a Reftek RT130 acquisition system. GPS receivers provided precise dating of seismic recordings. One solar panel and two batteries at each site provided the overall energy. Seismic data used in this work will be available at the French RESIF data archive centre (http://portal.resif.fr/) under seismic network code YV.

\subsection{Analysis of microseismic noise}

\subsubsection{Measurements of microseismic noise amplitudes}

To retrieve continuous information on seismic noise characteristics, we first performed an amplitude analysis of hour-long waveform signals, filtered by a Butterworth bandpass filter (2nd order, corner frequencies at $0.04 \mathrm{~Hz}$ and $0.09 \mathrm{~Hz}$, i.e., at periods of $\sim 11$ and $25 \mathrm{~s}$ ). This permits to quantify the root-mean-square (RMS) of the signal amplitude as function of time in the swell frequency band (Barruol et al., 2006; Davy et al., 2014). Such amplitude analysis is used to retrieve the swell height from the microseismic noise observation. Although the horizontal seismograms show larger amplitudes that could provide better accuracy in the analysis, we performed our measurements on the vertical seismograms, for several reasons: i) Vertical data are less affected by demonstrable artefacts than the horizontal, particularly concerning the problem of a diurnal thermal anomaly recorded by several of our stations and detailed below. ii) Inter-station coherence is found to be higher on the vertical component than on the horizontals.

\subsubsection{Measurement of the polarization of microseismic noise}

To characterize 3D elliptical ground motion caused by the swell, with the objective of retrieving swell azimuth, we performed a signal polarization analysis on the primary microseismic noise. For each hour-long signal window, we quantified the shape and the orientation of the ellipsoid characterizing ground motion, by calculating the degree of rectilinearity of particle motion in 3D (CLin), in the horizontal plane $(\mathrm{CpH})$ and in the vertical plane $(\mathrm{CpZ})$, as well as the apparent incidence angle $(\mathrm{Vpol})$ of ground motion (Barruol et al., 2006; Fontaine et al., 2007, 2009). This method is based on a Principal Component Analysis (PCA) (Pearson, 1901; Hoteling, 1933) that characterizes 3D elliptical ground motion by resolving the data into three components (East, North and Vertical). Barruol et al. (2006) described and used this method to characterize swell in French Polynesian islands in the southern Pacific, which, like the Iles Eparses are subject to strong swell arrivals from the Southern Ocean during the austral winters, from May to September.

\section{Austral swell analysis at Europa Island}

We analyze the amplitude, direction, and period of an austral swell generated in the southern Ocean between Africa and Antarctica, and that propagated northward into the Mozambique Channel. In the following section, this will be contrasted to a cyclonic swell generated more locally. We focus on these two examples of swells in order to discuss the feasibility of using seismological noise as a substitute for direct measurements of ocean wave height and swell direction, and to discuss the strengths and limitations of the approach.

The exemplary austral swell event originated from a strong storm that moved around Antarctica in August 2013 and generated a large swell, which spread north-to north-eastward into the Indian Ocean. Fig. 3 illustrates the propagation of this swell, through the spatio-temporal evolution of its significant wave height $\mathrm{Hs}$, and its direction of propagation $D p$, as predicted by the NOAA ocean wave model WaveWatchIII (WWIII) (Tolman and Chalikov, 1996). The swell propagated in the Mozambique Channel during the period of August 19-22, 2013. It first reached the southernmost station EURO (on Europa) on August 20 and station JNOV (on Juan de Nova) about twelve hours later. Station MAYO on Mayotte was reached on August 21. Also evident is the progressive northward attenuation of swell amplitude in the model, predicting a smaller signature at station MAYO (on Mayotte) and GLOR (on Glorieuses Islands) than at the two southern stations.

We extracted the modelled swell parameters $H s$ (significant wave height), $T p$ (swell period) and $D p$ (swell azimuth) at the closest grid point to each seismic station. These values are provided every $3 \mathrm{~h}$ on a 0.5 by $0.5^{\circ}$ grid. Fig. 4 compares the measured variations in amplitude of the vertical seismic component, filtered in the PM frequency band $(0.045-0.08 \mathrm{~Hz}$, i.e., between 12 and $22 \mathrm{~s}$ of period), to the predicted swell height $H s$ (in $\mathrm{m}$ ) for the period Aug. 17-24 and the 4 seismic stations. Amplitudes are plotted at the same scales, explaining that the two distant earthquakes on Aug. 17 and 21 produce very similar amplitudes at all four stations. For the swell-induced noise, which first increases and then decreases slowly over the four days, one can observe at the two southernmost stations EURO and JNOV a clear correlation between the amplitude of vertical ground displacement in the PM frequency band (blue) and the predicted swell height (black curve). This suggests that the PM noise is directly generated by swell interaction with the island. The correlation is less pronounced but still present at Mayotte and Glorieuses Islands in the north because swell height attenuates as it propagates northward in the Mozambique Channel (as predicted by Fig. 3). Also as predicted, we observe the progressive northward time shift in the microseismic peak that correlates well with the travel time of the swell front across the Mozambique Channel. Juan de Nova is about $630 \mathrm{~km}$ from Europa (Fig. 1), and the time difference of the maximum microseismic noise at the two stations is 13-15 h. Hence, the observed swell propagation velocity ranges from 42 to $49 \mathrm{~km} / \mathrm{h}$, as would be predicted for ocean waves of periods ranging from 15 to $18 \mathrm{~s}$, if one assumes the simple relationship $t=4 \pi d / g T$ (Haubrich et al., 1963; Chevrot et al., 2007; Sheen, 2014), where $t$ is the propagation time over the distance $d$ for an ocean wave of period $T$, and $g$ the gravitational acceleration.

The observed, direct correlation between $\mathrm{Hs}$ and the seismic noise amplitude suggests that a simple law can be deduced relating seismic noise amplitude to swell height. Fig. 5a compares the evolution of predicted wave height $H s$, and vertical root-meansquare (RMS) amplitudes in the primary and secondary noise bands at station EURO for the August 2013 swell event. We focus on the PM band, in order to quantify the actual local swell effect. Fig. 5b shows the relation between PM amplitude and $H s$, for all four stations in the Mozambique channel for this swell event: each point represents the RMS of microseismic noise amplitude at a given station and at a given time, with the corresponding $\mathrm{Hs}$ parameter extracted from the WWIII model. Each point represents a three-hour interval, which is time step of the Hs prediction; the noise measurement is extracted at these three-hour intervals from the hourly noise analyses. Our best estimate of a transfer function relating significant wave height $H s$ (in $\mathrm{m}$ ) in Fig. 5b to seismic noise amplitude $A$ (in microns) on the vertical component is the logarithmic relationship: $H s=2.5 \ln (1000 A)-7.6$. This empirical logarithmic relationship rises above the observational scatter only for Hs exceeding $\sim 3 \mathrm{~m}$, or $A$ exceeding 0.75 microns. The presumable reason is that small seismic amplitudes correspond to a wide range of wave heights rather than the single Hs predicted by the WWIII model, resulting in a modelling mismatch not captured by the simple functional relationship. Amplitudes exceeding the threshold were only measured at the southerly stations EURO and JNOV. Other swell events (shown in electronic supplement 1a) display a coherent transfer function for several austral and cyclonic events, 


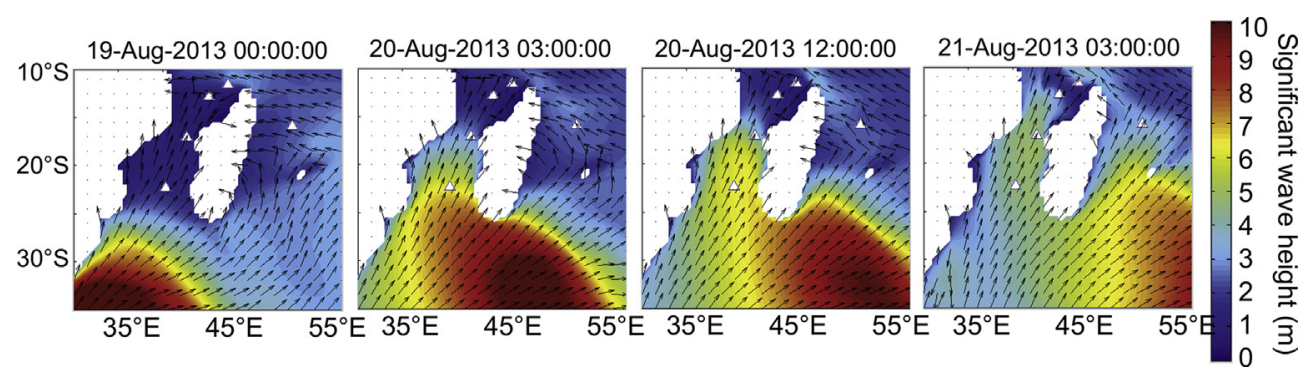

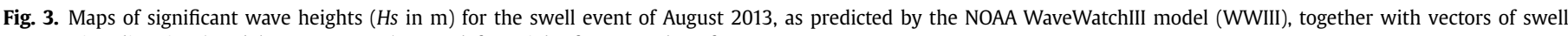
propagation direction (model parameter $D p$ ). From left to right, four snapshots from Aug. 19 to Aug. 21, 2013.

consistent with the $H s(A)$ relationship in Fig. 5b. This indicates that the measurement of the microseismic noise amplitude on the vertical seismogram can provide a good proxy for swell height, and that a relationship found at a given island is valid for different kind of swells. The approach is clearly better suited for strong swell events, as discussed for the example of Fig. 5b. The horizontal components of the seismograms have been similarly tested and processed (see electronic supplement 1b). Measurements of the seismic noise on the North horizontal component at EURO and for

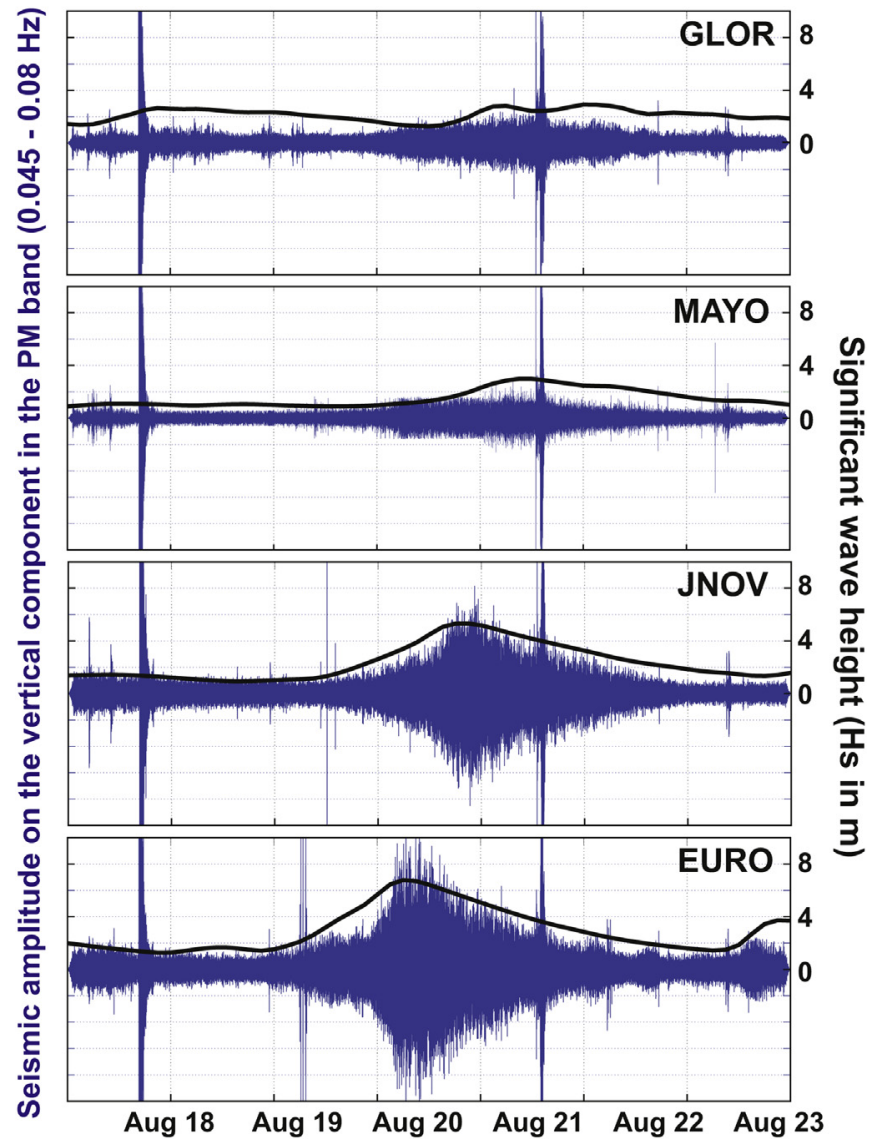

Fig. 4. Vertical seismic signal filtered in the primary microseismic band $(0.045-0.080 \mathrm{~Hz})$ at the four seismic stations in the Mozambique Channel, sorted geographically from south to north (bottom to top) and plotted at the same vertical scale. Superimposed is the significant wave height parameter $\mathrm{Hs}$ (in $\mathrm{m}$ on the right scale) extracted from the WWIII model. Seismic noise amplitude is well correlated with predicted swell height, particularly at the two southernmost stations. Note the presence of two earthquakes occurring during this period and detected by the National Earthquake Information Center (NEIC): a magnitude 6.1 event on the Southwest Indian ridge on 2013-08-17 at 16:32:31, and a magnitude 6.1 event in Mexico on 2013-08-21 at $12: 38: 33$. several austral and cyclonic events confirm the log-type of noise- $H s$ correlation and provides a very similar transfer function despite the larger noise amplitude (up to 3 microns).

Polarization analysis performed on hour-long seismic sequences during the period of Aug. 17-24 provides a quasi-continuous monitoring of the 3D polarization of ground displacement in the PM frequency band of $0.045-0.08 \mathrm{~Hz}$ (i.e., for swell periods between 12.5 and $22 \mathrm{~s}$ ). Fig. 6a shows that before the swell arrival, $\mathrm{CpZ}$ exceeds 0.9 (i.e., ground motion is almost linear in the vertical plane) and $\mathrm{CpH}$ varies between 0.6 and 0.8 . This describes a horizontal elliptical particle motion, compatible with the measured apparent incidence angle, and suggests that such ground motion in the PM frequency band occurs during low-swell, "background" activity. During the swell event (time interval shaded grey in Fig. 6), both $\mathrm{CpH}$ and $\mathrm{CpZ}$ increase and stabilize close to 1 . High $\mathrm{CpZ}$ and $\mathrm{CpH}$ indicate strong polarization in both the vertical and horizontal planes, indicating a quasi-linear, horizontal ground motion. Since
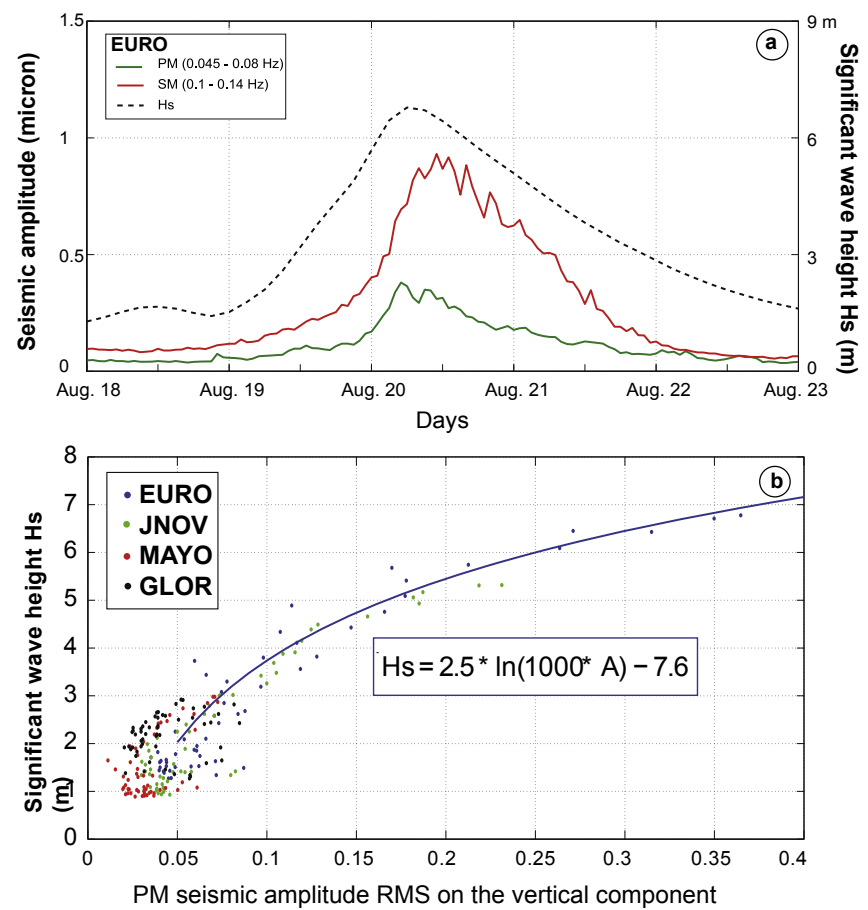

Fig. 5. a) RMS amplitude variations of primary and secondary microseismic noise (PM and SM) at station EURO, for the Aug. 2013 austral swell episode, together with significant swell height $H s$. b) Relationship between predicted swell amplitude $H s$ (in $\mathrm{m}$ ) from the WaveWatchIII (WWIII) model and observed vertical PM noise amplitude (in microns) at the four stations in the Mozambique Channel, for the Aug. 2013 swell episode. Amplitude measurements (dots, coloured by station) were extracted once every three hours and plotted against the Hs values predicted by for the WWIII mode points closest to the seismic stations. Solid line shows the empirical, logarithmic transfer function that best fits these observations. 


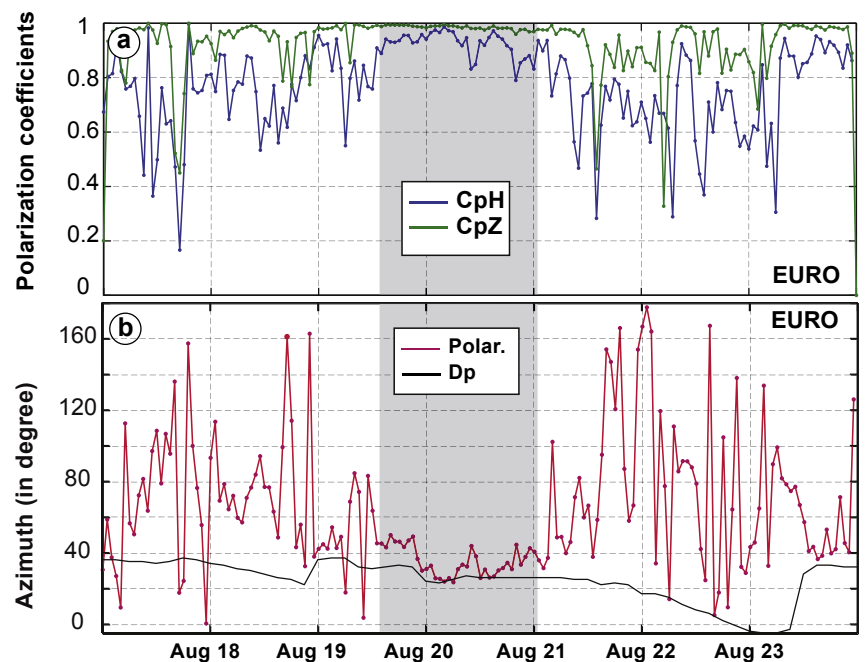

Fig. 6. a) Variation of the $\mathrm{CpH}$ and $\mathrm{CpZ}$ polarization coefficients over time, recorded by station EURO in the PM frequency band during the Aug. 17-24 2013 episode of austral swell. Grey shading indicates the peak swell period. b) Azimuth of ground polarization in the PM band during the same time at station EURO (red), together with swell azimuth obtained from the $D p$ parameter predicted by the NOAA WWIII model (black). During the swell peak, the observed azimuth is around $\mathrm{N} 030^{\circ} \mathrm{E}$, a value close to the predicted swell propagation $D p$ in Fig. 3.

$\mathrm{CpZ}$ was already high before the swell arrival, the strong increase of $\mathrm{CpH}$ above 0.9 better signals the start of the large swell episode. From $\mathrm{CpH}$ in Fig. 6a the swell arrival can be estimated at EURO around 12:00 on Aug. 19, consistent with the raw seismogram presented Fig. 4. The apparent incidence angle (not shown here) during the swell event is observed close to $90^{\circ}$, indicating that the ellipsoid characterizing the ground motion has its long axis close to the horizontal plane, which is consistent with findings for French Polynesia stations (Barruol et al., 2006).

Polarization of this August 2013 swell event (Fig. 6b) indicates a preferred azimuth trending $\mathrm{N} 030^{\circ} \mathrm{E}$ (with $180^{\circ}$ of ambiguity) during the maximum swell activity on Europa Island. The ground displacement during the swell episode can be therefore schematized by an ellipsoid extremely flattened in the vertical plane and strongly elongated in the horizontal plane. The ellipsoid long axis

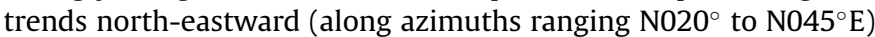
i.e., very close to the swell azimuth $D p$ predicted by the NOAA

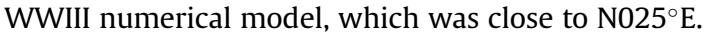

This analysis demonstrates that seismic data may provide useful quantitative information on ocean swell parameters. The swell period $T p$ can be directly read from spectrograms of seismograms. Its wave height $H s$ can be inferred, via the presented logarithmic relationship, from the microseismic noise amplitude $A$ in the swell frequency band (primary microseismic band). Ground polarization analysis may help determine the azimuth $D p$ of the incoming swell, as the example of station EURO shows. As a caveat, the good fit between the observed seismic polarization direction and $D p$ (as predicted by WWIII, presumably correctly) is likely helped by the fact that Europa Island is almost circular in shape. Barruol et al. (2006) have indeed shown that anisometric islands induce a local swell refraction, so that the azimuth of seismic noise polarization can be dominated by the island shape and not strictly by the swell azimuth.

\section{Cyclonic swell analysis at Tromelin Island}

We also analyzed the swell and the seismic signature induced by tropical cyclone "Felleng", which passed by Tromelin Island between Jan. 29 and Jan. 31 2013, while it was in its cyclone (i.e., most powerful) stage. The trajectory and intensity stages of the cyclone are shown in Fig. 7a.

For the period of Jan. 26 - Feb. 5 2013, Fig. 7b shows the variation of predicted, significant wave height $\mathrm{Hs}$, together with the distance and strength of the storm, from its depression to its cyclone stage. For the same time period, Fig. 7c shows the three components of seismic displacement at station TROM on Tromelin, filtered to the PM band; Fig. 7d shows the same records filtered to the SM band. The seismic traces show a clear increase in amplitude over the three components, associated with both the distance of the storm and its intensity. The roughly simultaneous increase in PM and SM amplitudes suggests that the sources of PM and SM are not far from each other and not far from Tromelin Island. Since the PM sources are thought to be swell waves pounding on the margins of the island, one can reasonably deduce that the SM sources are originating beneath the cyclone track. Indeed, Davy et al. (2014) independently confirmed this SM excitation mechanism for cyclone "Dumile" that occurred in early January 2013, which could be tracked across the spatially extended RHUM-RUM ocean-bottom seismic network using records from the SM noise band.

We determined the hourly RMS of the vertical amplitude of noise in the primary microseismic band, i.e., from seismograms filtered between 0.045 and $0.11 \mathrm{~Hz}$ (9-22 s period). Fig. 8a shows these variations measured on the three seismometer components $\mathrm{E}-\mathrm{N}-\mathrm{Z}$, together with the NOAA-predicted significant swell height $H s$ and the distance between station TROM and the meteorological centre of the cyclone.

When Felleng was still only a tropical depression (Jan 26-27, yellow line), at more than $1000 \mathrm{~km}$ from Tromelin, the seismic amplitude was low on all three components, of the order of 1 micron. During this "quiet" period, the E component shows, however, a clear diurnal peak in amplitude lasting 10-12 h. On the $\mathrm{N}$ and $\mathrm{Z}$ components, this daily peak is also visible but only at periods longer than those of the PM band, and with a generally smaller amplitude. Since this increase starts every day at sunrise, ends at sunset, and is absent on cloudy days, we interpret this signal as induced by large temperature variations on the seismic sensor. The seismometer was installed at the surface, covered by an insulating cap (a wooden box internally lined by several foam layers), but sitting on a concrete base that likely conducted the heat of the sun and/or deformed (tilted) due to it. To shield against such temperature variations, seismometers are usually buried in holes but this was impossible on the rock-like coral atoll of Tromelin.

As the tropical depression intensified into a storm on Jan. 28, and into a tropical cyclone on Jan. 29, the microseismic noise as shown Fig. 8a increased quickly, to up to 5 microns on the $\mathrm{E}$ component, 10 microns on $\mathrm{N}$, and 2 microns on V. Surprisingly, during maximum intensity, the RMS of the PM amplitude displays two independent peaks separated by an abrupt decrease. This local minimum occurred around Jan. 30 around 00:00 as the cyclone eye was at its closest distance to Tromelin. The raw seismograms of Fig. 7c also show this temporary lull, especially in the PM frequency band. Interestingly, the SM band (Fig. 7d) does not show any excess energy at the time of the PM gap, which might be expected if more intense, shorter-period wave activity transferred energy to the SM band. Fig. 7d instead shows a slight decrease in amplitude, synchronous with the temporary energy lull in the PM band, though less pronounced.

We suggest that this seismic signature represents cyclone dynamics, as follows. The first peak occurred on Jan. 29 , as the cyclone was still located north of Tromelin, its swell impacting the island from the NE, i.e., normal to the island's long axis. Seismic amplitude decreased later on Jan. 29, as the cyclone decelerated (coloured dots representing the cyclone's meteorological eye Fig. 7a are more 

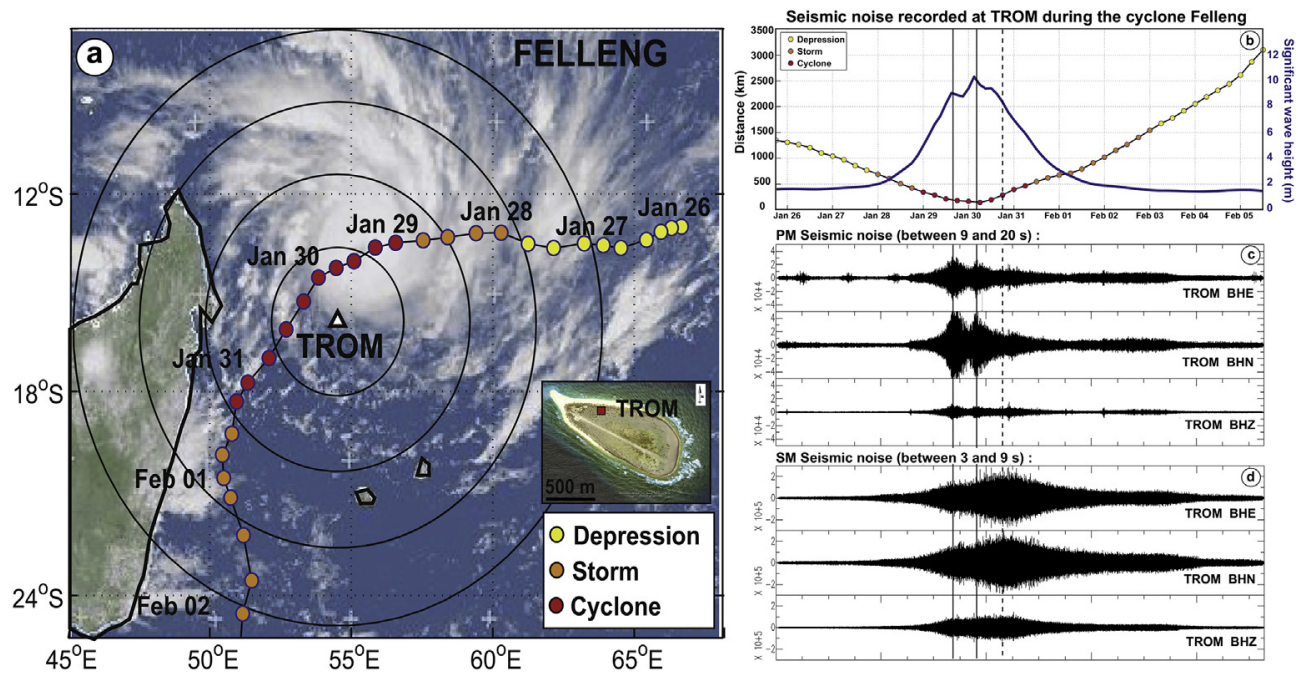

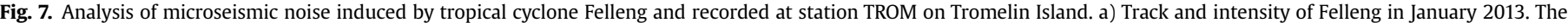

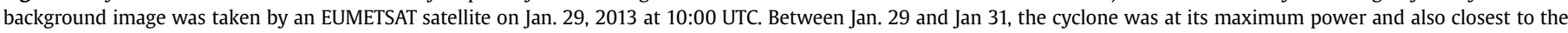

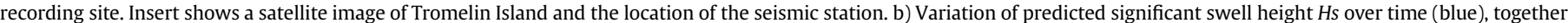

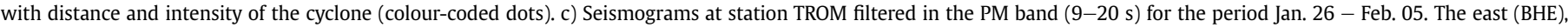

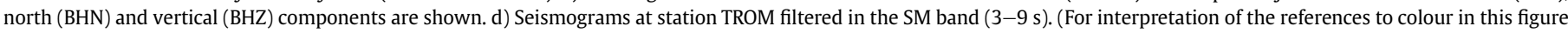
legend, the reader is referred to the web version of this article.)
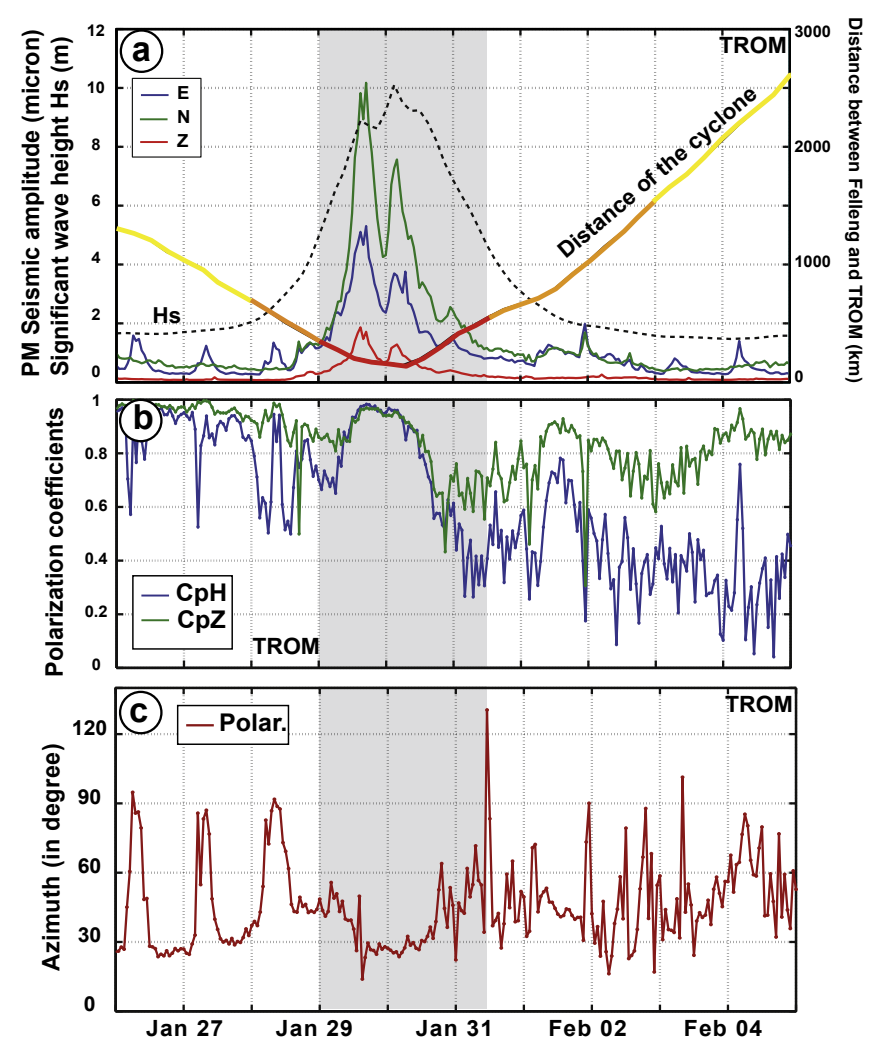

Fig. 8. PM amplitude and polarization at TROM during cyclone Felleng. a) Variation of the root-mean-square amplitude (in microns) on the three seismological components of station TROM filtered in the PM band, between Jan. 26 and Feb 5, 2013. Superimposed is the variation of the calculated $H s$ swell amplitude (in $\mathrm{m}$, on the left axis) and the distance of the cyclone centre to the station (in $\mathrm{km}$ on the right axis), together with cyclone intensity (indicated in the same colours as in Fig. 7a). Shaded area represents the period during which Felleng was meteorologically categorized as being in cyclone stage. b) Variation of the $\mathrm{CpH}$ and $\mathrm{CpZ}$ polarization coefficients over time during the cyclone episode. c) Ground polarization analysis indicating the azimuth of the ellipsoid long axis. closely spaced during this time) and moved slowly to the SW. The second peak amplitude occurs early on Jan. 30, as the cyclone accelerated, moved toward the SSW, and passed west of Tromelin. Hence, microseismic noise is likely influenced by both the position of the cyclone centre that controls the azimuth of the swell that hits the island, but also by its displacement velocity. For a cyclone passing west of a seismic station in the southern hemisphere, the swell results from the combined effects of the winds rotating clockwise around the cyclone's eye and the southward motion of the storm. This induces a swell maximum on the eastern and southeastern sides of the cyclone, which is consistent with the observed maximum late on Jan. 29 as the eye was located NNW to Tromelin. Our seismic measurements of PM and SM amplitudes are therefore consistent with a slight decrease in cyclone intensity combined with a slight deceleration early on Jan. 30, 2013.

On Jan. 31, as the cyclone was downgraded to a tropical storm and moved away from TROM, PM noise quickly decreased on all three components to amplitudes smaller than 1 micron (Figs. 7c and 8a). In Fig. 8a, the increase in noise amplitude occurs at the same time as the predicted increase in swell height. On the other hand, the decrease in predicted swell height seems to occur $12-24 \mathrm{~h}$ after the observed decrease in seismic noise. This time lag may reflect a limitation of the WWIII numerical model, or it could be real, reflecting the fact that short-period swell (within the SM band) may dominate the microseismic noise in the wake of the cyclone.

Analogous to the austral swell events, we can determine the transfer function between seismic PM noise amplitude and swell height $H s$ from cyclone passage events. Results are presented in Electronic Supplement 2a for cyclone Felleng, but also for cyclones Imelda (April 8-15, 2013) and Dumile (Dec. 29, 2012-Jan 06, 2013), and for an austral swell event (Jun. 18-22, 2013) that affected Tromelin. Interestingly, these events are again compatible with a single, logarithmic relationship, the best estimate for which is $\mathrm{Hs}=$ $1.9 \ln (1000 A)-5.9$ for Tromelin.

The clear increase in the SM amplitude as the storm approaches and strengthens (seen the seismograms of Fig. 7d) is likely related to the increase of stationary waves excited within the storm system, as described by Davy et al. (2014) for the cyclone Dumile. They 
showed that the maximum of SM sources were located close to the storm centre and much more active during its cyclone stage, which is fully consistent with the present observations made on Tromelin for cyclone Felleng. The slight decrease of SM amplitude early on Jan. 30 likely indicates a slight decrease in storm intensity.

Polarization of ground displacement on Tromelin Island during cyclone Felleng is strong in the PM frequency band, both in the vertical and horizontal planes (Fig. $8 \mathrm{~b}$ ). Both $C p Z$ and $C p H$ reach a maximum close to 1 on Jan. 29 around 12:00, and remain high during the time interval when the cyclone centre was closest to the island, early on Jan. 30. Polarization decreases later on Jan. 30, as the swell height $H s$ decreases and the cyclone moves southward, away from Tromelin (Fig. 7a). The end of the cyclone episode on Jan. 31 is associated with a clear decrease in the polarization coefficients $\mathrm{CpH}$ and $\mathrm{CpZ}$, i.e., a loss of any discernable polarization. Strong daily variations in $\mathrm{CpH}, \mathrm{CpZ}$ and azimuth visible in Fig. 8b and c between Jan. 26 and Jan. 29, are clearly attributed to the east component variations likely due to the temperature artefact discussed earlier, rather than being swell-related.

Polarization during the cyclone shows an apparent incidence angle close to $90^{\circ}$ (not shown here) indicating dominantly horizontal ground motion. The azimuth of polarization varies between $\mathrm{N} 045$ and $\mathrm{N} 025^{\circ} \mathrm{E}$, with a stabilization around $\mathrm{N} 030^{\circ} \mathrm{E}$ at maximum cyclone intensity (Fig. 8c). During the cyclone phase, the observed azimuth of the ground polarization is rather stable, despite the fact that the theoretical wave direction is expected to rotate as the cyclone moves southwards. This is likely explained by the elongated shape of Tromelin Island and its associated shallow waters, which strike along a $\mathrm{N} 110^{\circ} \mathrm{E}$ to $\mathrm{N} 120^{\circ} \mathrm{E}$ trending ridge (see insert of Fig. 7a, and the Litto3D - Eparses 2012 bathymetric map on the web site of the hydrographic service of the French Marine, http:// data.shom.fr). We propose that this anisometric ridge induces a swell rotation near parallel to the ridge axis, which would explain why the swell interacts with the shallow waters in the neighbourhood of Tromelin Island at a very stable azimuth perpendicular to the ridge axis, i.e., close to $\mathrm{N} 030^{\circ} \mathrm{E}$.

Hence, we find that PM band noise recorded on an island during a tropical cyclone shows ground polarization dominantly contained within the horizontal plane, as previously described for island stations in French Polynesia (Barruol et al., 2006). This clearly contrasts with SM band noise from ocean bottom observations near Tromelin (for cyclone Dumile occurring in early January 2013), which was dominated by vertical polarization (Davy et al., 2014). This illustrates the complexity of the signals and the diversity of the involved processes in the various frequency bands, as shown for instance by Beucler et al. (2014) and modelled by Gualtieri et al. (2014). PM broadly result from swell-induced pressure variation on the seafloor close to the coast whereas SM results mainly from standing waves developing in the open ocean, transmitting pressure waves to the deep sea floor (Longuet-Higgins, 1950).

\section{Long-term swell variations at Europa and Tromelin islands}

A continuous analysis of PM noise amplitudes on the vertical component over a period of several months gives a good idea of swell impact on these islands, as seen from terrestrial seismological measurements. Fig. 9 illustrates the variations of RMS noise amplitude recorded at the station EURO (Fig. 9a) and TROM (Fig. 9b) (hourly samples), together with the predicted swell height $\mathrm{Hs}$ (in $\mathrm{m}$ ) extracted from the WWIII NOAA model for the period Feb. - Sep. 2013 at EURO and Nov. 2012-Jul. 2013 at TROM. Shaded bars mark dominant austral and cyclonic swell events, for which a clear correlation between $\mathrm{Hs}$ and microseismic noise is evident. Most peaks observed in the microseismic noise are well correlated with swell or cyclonic events that generate ocean waves higher than $4 \mathrm{~m}$. On
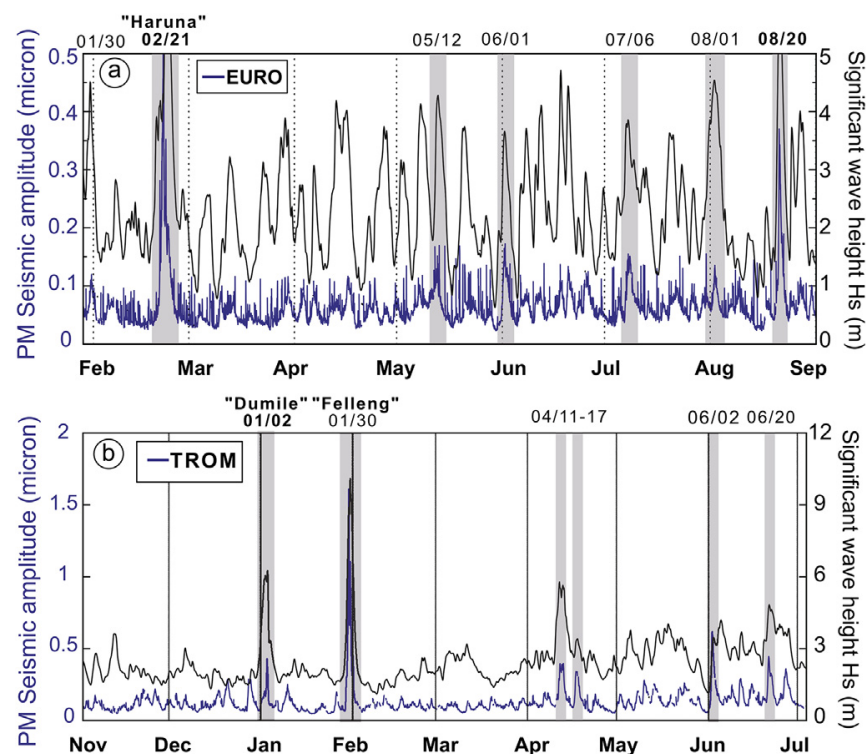

Fig. 9. Long-term variation of PM vertical seismic noise amplitude (in blue) at station EURO for the period Feb-Sep. 2013 (panel a), and at station TROM for the period Nov. 2012-Jul. 2013 (panel b). Black curves in both panels show swell height $H s$ (in $\mathrm{m}$ ) as predicted by the WaveWatchIII model. The time periods of cyclonic and of large austral swells are shaded grey and labelled. Good correlation is observed between PM microseismic noise and some large swell events, and particularly with the swell induced by tropical cyclones Dumile and Felleng at TROM, and Haruna at EURO (stations located near the tracks of the respective storms). (For interpretation of the references to colour in this figure legend, the reader is referred to the web version of this article.)

the other hand, not all swell events are well correlated to microseismic peaks. In particular, swell events of $H s$ amplitudes smaller than 3-4 $\mathrm{m}$ are not reliably detected by the microseismic noise. Hence, evaluating swell height from microseismic noise is more reliable for large swell. This limitation is not so penalizing since our approach is intrinsically developed for monitoring large swell events that may have strong impact on islands and coasts. Another caveat is that some swell $\mathrm{Hs}$ peaks predicted as higher than $4 \mathrm{~m}$ do not generate any detectable signature in the microseismic noise amplitude. Either the swell modelling may sometimes overestimate true swell height, or the actual dominant swell period is shorter than $10 \mathrm{~s}$, in which case it would have been filtered out of our analysis. In order to better constrain these relationships, local ocean buoys should validate swell models, but they are unfortunately not available in this area.

\section{Conclusion}

By analyzing the microseismic noise recorded by seismological stations installed in the Iles Eparses in the Mozambique Channel and on Tromelin Island, we demonstrate that the continuous recording of the ground vibration provides useful quantitative insights into the ocean swell impacting the islands. This approach appears particularly well suited to the evaluation and quantification of strong swell events. We show that the amplitude of vertical microseismic noise filtered between 10 and $20 \mathrm{~s}$ period (primary microseismic noise band) provides a good proxy for swell height $H s$. Swell period $T p$ may be retrieved by spectral analysis and swell azimuth $D p$ may be retrieved under certain favourable conditions by polarization analysis of the ground motion. Characterizing swell parameters from terrestrial recordings of seismic noise has limitations: swell amplitude is better constrained for large swell heights, and swell azimuth is better determined for roughly circular 
islands (such as Europa) than for anisometric islands (such as Tromelin) because the latter cause swell refractions along the coast. In summary, terrestrial seismic recordings on remote and harsh islands may provide a robust and simple way to retrieve swell parameters from ground seismic observation, without deploying any marine instruments. Seismology can therefore efficiently participate in environmental studies evaluating the physical impact of ocean waves on coastal and reef environments.

\section{Acknowledgements}

This research was supported by France's "Iles Eparses" program (2011-2013) managed by CNRS-InEE (Institut Ecologie et Environnement) with the financial support of CNRS-InEE, CNRS-INSU (Institut National des Sciences de l'Univers), IRD (Institut de Recherche pour le Développement), AAMP (Agence des Aires Marines Protégées) and the logistic support of TAAF (Terres Australes et Antarctiques Françaises). This work was also supported by the RHUM-RUM project (www.rhum-rum.net) funded by the ANR (Agence Nationale de la Recherche) in France (project ANR-11BS56-0013), and by the DFG (Deutsche Forschungsgemeinschaft) in Germany. Additional funding has been provided by the INSU program SYSTER, by the OSU (Observatoire des Sciences de l'Univers) Réunion. Portable seismometers were provided by the Alfred Wegener Institut (AWI) in Bremerhaven. Seismic data used in this work will be available at the French RESIF archive centre (http:// portal.resif.fr/) under the network code YV. Thanks to D. Reymond for the Seismic Toolkit software (STK, available at http:// seismic-toolkit.sourceforge.net) and particularly for the SVDS program that has been used for the swell polarization analysis. We thank R.B. Herrmann for the program to compute the power spectral density (Hermann, 2013) and Météo France for providing data about the cyclone. This is IPGP contribution 3691.

\section{Appendix A. Supplementary data}

Supplementary data related to this article can be found at http:// dx.doi.org/10.1016/j.actao.2015.10.015.

\section{References}

Ardhuin, F., Stutzmann, E., Schimmel, M., Mangeney, A., 2011. Ocean wave sources of seismic noise. J. Geophys. Res. 116, C09004. http://dx.doi.org/10.1029/ 2011 jc006952.

Barruol, G., Reymond, D., Fontaine, F.R., Hyvernaud, O., Maurer, V., Maamaatuaiahutapu, K., 2006. Characterizing swells in the Southern Pacific from seismic and infrasonic noise analyses. Geophys. J. Int. 164, 516-542. http:// dx.doi.org/10.1111/J.1365-246X.2006.02871.x.

Barruol, G., Sigloch, K., 2013. Investigating La réunion hot spot from crust to core. Eos, Trans. Am. Geophys. Union 94, 205-207. http://dx.doi.org/10.1002/ 2013 eo230002.

Beucler, É., Mocquet, A., Schimmel, M., Chevrot, S., Quillard, O., Vergne, J., Sylvander, M., 2014. Observation of deep water microseisms in the North Atlantic Ocean using tide modulations. Geophys. Res. Lett. 2014, GL062347.
http://dx.doi.org/10.1002/2014GL062347.

Bromirski, P.D., Duennebier, F.K., 2002. The near-coastal microseism spectrum: spatial and temporal wave climate relationships. J. Geophys. Res. 107 http:/ dx.doi.org/10.1029/2001JB000265.

Bromirski, P.D., Duennebier, F.K., Stephen, R.A., 2005. Mid-ocean microseisms. Geochem. Geophys. Geosyst. 6, Q04009. http://dx.doi.org/10.1029/ 2004GC000768.

Cessaro, R.K., 1994. Sources of primary and secondary microseisms. Bull. Seismol. Soc. Amer. 84, 142-148.

Chevrot, S., Sylvander, M., Benahmed, S., Ponsolles, C., Lefèvre, J., 2007. Source locations of secondary microseisms in Western Europe: evidence for both coastal and pelagic sources. J. Geophys. Res. 112 http://dx.doi.org/10.1029/ 2007JB005059.

Darbyshire, J., Okeke, E.O., 1969. A study of primary and secondary microseisms recorded in Anglesey. Geophys. J. R. Astron. Soc. 17, 63-92.

Davy, C., Barruol, G., Fontaine, F.R., Stutzman, E., Sigloch, K., 2014. Tracking major storms from microseismic and hydroacoustic observations on the seafloor. Geophys. Res. Lett. 41 http://dx.doi.org/10.1002/2014GL062319.

Davy, C., Stutzman, E., Barruol, G., Fontaine, F.R., Schimmel, M., 2015. Sources of secondary microseisms in the Indian Ocean. Geophys. J. Int. 202, 1180-1189. http://dx.doi.org/10.1093/gji/ggv221.

Essen, H.-H., Krüger, F., Dahm, T., Grevemeyer, I., 2003. On the generation of secondary microseisms observed in northern and central Europe. J. Geophys. Res. Solid Earth 108, 2506. http://dx.doi.org/10.1029/2002JB002338.

Fontaine, F.R., Barruol, G., Kenneth, B.L.N., Bokelmann, G.H.R., Reymond, D., 2009 Upper mantle anisotropy beneath Australia and Tahiti from P-wave polarization - implication for real-time earthquake location. J. Geophys. Res. 114 http:/ dx.doi.org/10.1029/2008JB005709.

Fontaine, F.R., Barruol, G., Tommasi, A., Bokelmann, G.H.R., 2007. Upper mantle flow beneath French Polynesia from shear-wave splitting. Geophys. J. Int. 170, 1262-1288, http://dx.doi.org/10.1111/j.1365-246X.2007.03475.x.

Friedrich, A., Krüger, F., Klinge, K., 1998. Ocean-generated microseismic noise located with the Gräfenberg array. J. Seismol. 2, 47-64.

Gualtieri, L, Stutzmann, E., Farra, V., Capdeville, Y, Schimmel, M., Ardhuin, F, Morelli, A., 2014. Modelling the ocean site effect on seismic noise body waves. Geophys. J. Int. 197, 1096-1106. http://dx.doi.org/10.1093/gji/ggu042.

Hasselmann, K., 1963. A statistical analysis of the generation of microseisms. Rev. Geophys. 1, 177-210.

Haubrich, R.A., Munk, W.H., Snodgrass, F.E., 1963. Comparative spectra of microseisms and swell. Bull. Seismol. Soc. Amer. 53, 27-37.

Hermann, R.B., 2013. Computer Program in Seismology: an evolving tool for instruction and research. Seismol. Res. Lett. 84, 1081-1088. http://dx.doi.org/ $10.1785 / 0220110096$.

Hoteling, H., 1933. Analysis of a complex of statistical variables into principal components. J. Educ. Psychol. 24, 417-441.

Koper, K.D., Buriaciu, R., 2015. The fine structure of double-frequency microseisms recorded by seismometers in North America. J. Geophys. Res. 120, 1677-1691. http://dx.doi.org/10.1002/2014JB011820.

Longuet-Higgins, M.S., 1950. A theory of the origin of the microseisms. Phil. Trans. Roy. Soc. 243, 1-35.

Obrebski, M.J., Ardhuin, F., Stutzmann, E., Schimmel, M., 2012. How moderate sea states can generate loud seismic noise in the deep ocean. Geophys. Res. Lett. 39, L11601. http://dx.doi.org/10.1029/2012gl051896.

Pearson, K., 1901. On lines and planes of closest fit to system of points in space. Phil. Mag. 2, 559-572.

Peterson, J., 1993. Observation and modeling of seismic background noise. U.S. Geol Surv. Open File Rep. 93-322, 1-95.

Reading, A.M., Koper, K.D., Gal, M., Graham, L.S., Tkalčić, H., Hemer, M.A., 2014. Dominant seismic noise sources in the Southern Ocean and West Pacific, 2000-2012, recorded at the Warramunga Seismic Array, Australia. Geophys. Res. Lett. 41 http://dx.doi.org/10.1002/2014GL060073.

Sheen, D.H., 2014. Microseisms from huge Indian Ocean storms in May 2007. Geosciences J. 18, 347-354. http://dx.doi.org/10.1007/s12303-013-0068-1.

Tolman, H.L., Chalikov, D.V., 1996. Source terms in a third-generation wind wave model. J. Phys. Oceanogr. 26, 2497-2518. 